\title{
ASSESSING THE IMPACT OF CERTAIN EXERCISES ON THE SPATIAL HEAD POSTURE
}

\section{ELŻBIETA SZCZYGIEŁ, BARTOSZ SIERADZKI, AGATA MASŁOŃ, JOANNA GOLEC, DOROTA CZECHOWSKA, KAROLINA WĘGLARZ, RADOSŁAW SZCZYGIEŁ, and EDWARD GOLEC}

Bronislaw Czech Physical Academy Education, Kraków, Poland

Orthopedic Rehabilitation Institute, Clinical Rehabilitation Division, Motor Rehabilitation Department

\begin{abstract}
Objectives: The head constitutes $6 \%$ of the total body weight, which is linked to the cervical spine and all other joints through the kinematic chain by various muscles. The forward head posture is one of the most common postural disorders and seems to be especially dangerous. The goal of the work was to assess the impact of 4 weeks of training neck and nape muscles on the head posture. Material and Methods: The subjects were 20 participants, who performed neck exercises for 20 days. The head posture in a sagittal and frontal plane was assessed photogrammetrically twice: before and after the exercises. The following have been used for the assessment: craniovertebral (CV) angle, head tilt angle (HT), and frontal head tilt angle (FHT). Results: After a 20-day program of neck and nape exercises the values of specific angles were compared. The results indicated significant changes in the head posture. In the sagittal plane: the average value of the $\mathrm{CV}$ angle before the training was $47.17^{\circ}$, and $50.82^{\circ}$ after the training; the average value of the HT angle before the exercises was at $20.99^{\circ}$, and $24.31^{\circ}$ after. In the frontal plane the average value of the FHT angle before the exercises was at $2.71^{\circ}$, and after 20 days of training the average value of this angle decreased to $2^{\circ}$. Conclusions: The results demonstrate that a short, home-based targeted exercise program can improve head posture. Int J Occup Med Environ Health. 2019;32(1):43-51
\end{abstract}

Key words:

forward head posture, head, exercises, craniovertebral angle, job workers, prophylactic of neck pains

\section{INTRODUCTION}

The head constitutes $6 \%$ of the total body weight, which is linked to the cervical spine and all other joints through the kinematic chain by various muscles. The forward head posture (FHP) is one of the most common postural disorders and seems to be especially dangerous. The forward head posture is a head-on-trunk misalignment and is described as the excessive anterior positioning of the head in relation to a vertical reference line [1]. It has been calculated that a frontal interposition of the head at $5 \mathrm{~cm}$ in reference to the body's axis increases its weight at $10 \mathrm{~kg}$ [2]. The first stage of functional changes resulting from an incorrect head posture consists in numerous compensa- tions. What can be noticed are the non-physiological angulation of the lower cervical section with a simultaneous straightening of the upper part of the cervical section [3]. The cervicothoracic junction undergoes a gradual overextension. It is a section where the mobile cervical part of the spine changes into the less movable thoracic section. Distortions in the myofascial system occur, which may result in head [4] or neck pains [5]. Fernández-de-las-Peñas et al. [4] have determined that as the head tilt angle in the sagittal plane increases, the mobility of the cervical spine decrease. Griegel-Morris et al. suggest that a head positioned in protraction has a negative impact not only on the cervical spine but also the thoracic spine and shoulder

Received: October 27, 2017. Accepted: May 14, 2018

Corresponding author: Elżbieta Szczygieł, Bronislaw Czech Physical Academy Education, Motor Rehabilitation Department, al. Jana Pawła II 78, 31-571 Kraków, Poland (e-mail: elzbietasz@gmail.com). 
blades [6]. An incorrect head posture results in a change of the breathing model. Research by Szczygieł et al. [7] indicate that a lack of the head's axial symmetry in the 3 dimensional aspect results in a limited mobility of the chest, while Han et al.'s [8] research indicate that the forward head posture reduces the vital capacity.

Literature usually includes descriptions of the effects of exercises aiming to mitigate the symptoms of the cervical pain syndrome. Taking into consideration the above mentioned consequences of an incorrect head posture, it seems right to try and form a prevention program for these dysfunctions. For that reason, the goal of the research was to assess the impact 4 weeks of training neck and nape muscles have on the head posture.

\section{MATERIAL AND METHODS}

Many authors emphasize that office workers and people who work in front of a computer, in a special way are at risk of improperly holding their heads. For that reason, 21 healthy females aged 30-60 years old participated in the research (Table 1). Subjects were recruited from one of the public offices in Kraków, and their work seniority in front of a computer had not been shorter than 5 years. According to a clinical assessment, the heads of the people qualified for the exercise program were misaligned. The research group was very diverse in terms of age and work seniority (Table 1).

Before initiating the research the women had filled out a survey in which they had confirmed the character of their work, number of working hours a day, and number of years by the desk. Any surgeries, injuries, and other medi- cal conditions which might have resulted in pains in the head area or impacted its position, were ruled out.

The research was carried out after receiving a written permission from each participant.

Data concerning 20 women has been included in the final analysis. One person did not finish the exercise program, thus was excluded from the research. The training period lasted 20 days.

The photogrammetry method was used for assessing the position of the head. According to many authors it constitutes a simple and objective technique for measuring the posture of different parts of the body and has good validity when analyzing head and neck posture $[9,10]$. The presented research included the use of a Canon EOS 1200D digital camera. The researched people were asked to wear a light sports shirt, take off their shoes and socks. Photos were taken in a natural position standing on both feet, right towards the sagittal plane and facing the frontal plane. The landmarks were joined on the participant's rights side using double sided tape: the spinous process of $\mathrm{C}$, the external corner of the eye, the tragus of the ear.

The taken pictures were not shown to the participants in order to avoid the lack of reliability of the measurements by intentionally repositioning the head or straightening the entire torso. The participants were asked to bend and straighten the head 3 times just before the picture was taken in order to achieve the optimal, natural head posture. A tripod (HAMA Star 05) was used during the research in order to take the sharpest possible photos. The photos were taken from $0.3 \mathrm{~m}$ with the tripod height set at $1.5 \mathrm{~m}$.

Table 1. Characteristics of the research group of the 20 females from the public office in Kraków, Poland

\begin{tabular}{lccccc}
\hline \multicolumn{1}{c}{ Variable } & Min. & Max & Me & M & SD \\
\hline Age [years] & 30 & 60 & 45.5 & 45 & 9.1 \\
Work seniority [years] & 5 & 38 & 18.5 & 18.2 & 10.2 \\
Working hours a day [h] & 4 & 12 & 8 & 8.2 & 2.4 \\
\hline
\end{tabular}


The taken photos were saved with the GNU Image Manipulation Program (GIMP) for Windows where 3 angular measurements were performed to illustrate the positioning of the head in reference to the neck: 2 measurements in the sagittal plane (A, B) and 1 in the frontal plane $(\mathrm{C})$ :

- A: craniovertebral (CV) angle - the angle between the intersection of a horizontal line passing through the $\mathrm{C} 7$ spinous process and a line joining the midpoint of the tragus of the ear to the $\mathrm{C} 7$ spinous process (Figure 1) [5,11]. - B: head tilt (HT) angle - the angle between the tragus of the ear to the canthus of the eye and the horizontal (Figure 2) [5].

- C: frontal head tilt (FHT) angle - this angle formed between the line joining inferior margins of both ears and the horizontal line, is measure of lateral flexion of head (Figure 3), [5,12,13].

After 20 days of training the angle values were compared in order to verify the achieved therapeutic effects. The posture in the photographs was assessed by 1 evaluator.

\section{Used training}

The participants were given a list and description (with illustrations) for each exercise and were required to demonstrate their ability to perform each exercise correctly. The exercises had been selected on the basis of an overview of source literature [14-17]. Their goal was to increase the stability and flexibility of the myofascial tissue within the cervical spine.

The training program included 7 exercises. Each exercise was repeated 10 times.

- Exercise 1. Initial position: laying on the stomach and forearms, pulling shoulder blades together. Motion: pressing the chin against the sternum, then lifting the head to the torso line, and then straightening the head looking at the ceiling.

- Exercise 2. Initial position: supported kneel. Motion: keeping the head in one line with the torso, in such

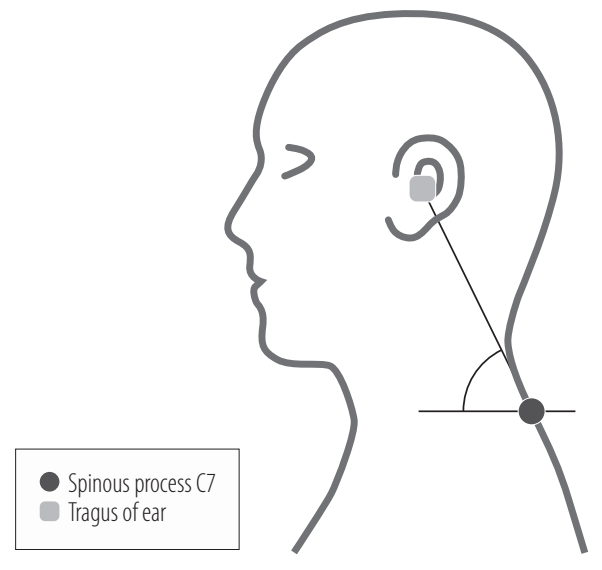

Figure 1. Photogrammetric method of measuring the craniovertebral $(\mathrm{CV})$ angle

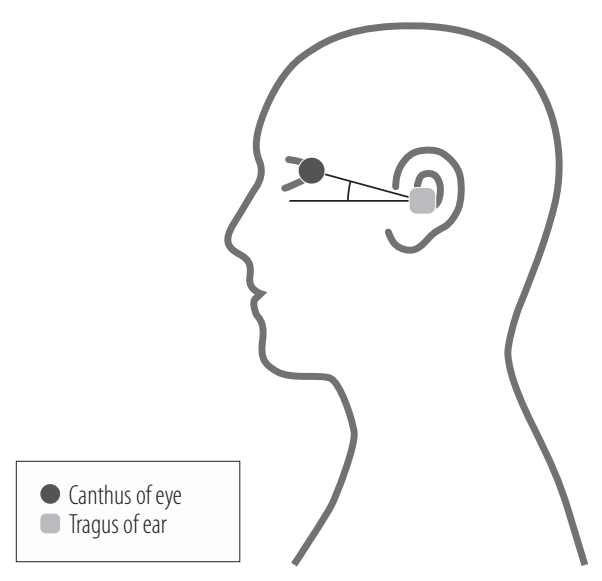

Figure 2. Photogrammetric method of measuring the head tilt (HT) angle

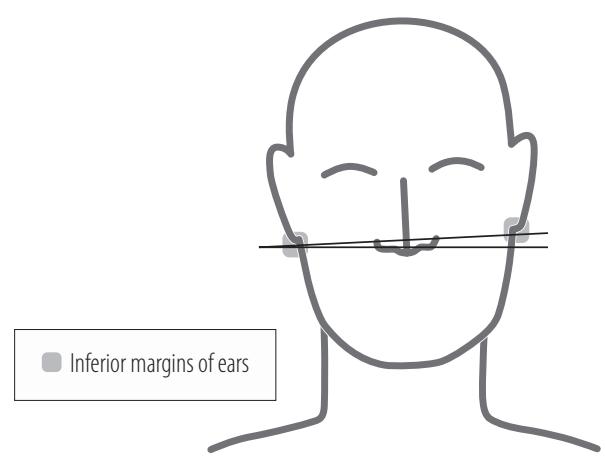

Figure 3. Photogrammetric method of measuring the frontal head tilt (FHT) angle 
a position placing one hand in front, counting to 15 , returning to the initial position and then changing the hand.

- Exercise 3. Initial position: laying on the back with bent knees, both feet on the ground hands on the occiput. Motion: slowly moving the head towards the sternum without lifting the head from the floor. Trying to touch the sternum with the jawbone.

- Exercise 4. Initial position: sitting on a chair with the back pressed against the support, hands falling loosely against the torso, looking straight ahead, the head positioned in accordance with the axis. Motion: moving the shoulders back towards the ear and then loosening the muscles, only the shoulders work.

- Exercise 5. Initial position: sitting comfortably on a chair with the back pressed against the support, head positioned in accordance with the axis. Motion: holding the opposite side of the head with the hand and bending the head so that the ear moves towards the shoulder. Stretching until a moment of a slight tension, keeping that position for $15 \mathrm{~s}$ while breathing naturally.

- Exercise 6. Initial position: standing with the back against a wall and looking straight ahead. Motion: while pressing fingers against the chin, delicately and slowly perform a retraction motion with the head.

- Exercise 7. Initial position: standing with the back against a wall, looking straight ahead. Motion: slowly turn the head horizontally and stop when the maximum value is reached (right and left).

The exercises were performed 5 times a week for 4 weeks at home. The pace of the exercises was slow, what counted was precision and accurateness. These exercises were performed in various positions in order to engage specific muscle sections. The main goal of this training was to increase the stability and flexibility of the myofascial tissue within the cervical spine. A presentation of the exercises, individual instructions, and eliminating incorrect motions took place during the initial meeting.

\section{Statistical analysis}

The statistical analysis of the data was performed with the Statistica 10.0 software. Two measurements of an individual patient, before and after the treatment, were regarded as a matched pair. The t-test was used for dependent samples. A statistical significance of 0.05 was set for all conducted tests. The significance of differences between the average scores before and after the training was researched.

Furthermore, the impact of selected variables such as age, work seniority, and number of work hours a day, have been researched in reference to the changing values of the analyzed head and neck angles.

\section{RESULTS}

\section{Craniovertebral (CV) angle}

The impact of the conducted exercises on the $\mathrm{CV}$ angle was researched (Figure 1). The average value for this angle before the training was $47.17^{\circ}$, at $\mathrm{SD}=4.85$. The largest value oscillated around $57.94^{\circ}$, and the lowest at $38.71^{\circ}$. After the conducted rehabilitation the average value for the $\mathrm{CV}$ angle increased to $50.82^{\circ}$. After 20 days the highest result increased to $58.97^{\circ}$, and the minimal value of this set to $39.92^{\circ}$.

Based on the conducted test it has been determined that there is a significant difference in the measurements of the $\mathrm{CV}$ angle before and after the training. The conducted exercises significantly increase the value of this angle with the average difference being $3.66^{\circ}$. The p-value significance level is equivalent to 0.0006 . The t-test value stands at -4.1385 (Figure 4).

\section{Head tilt (HT) angle}

When comparing the measurements of the HT angle it was noticed that the average value before the training was at $20.99^{\circ}$ with a quite large SD $=9.18$ (Figure 2). The highest value for this angle was $35.56^{\circ}$, and the lowest was $1.46^{\circ}$, which indicated a large range of measurements, 
$\mathrm{R}=34.1$. The difference of average values for the HT angle after the rehabilitation was at $-3.33^{\circ}$. The average result after training was at $24.31^{\circ}$ where the maximum value was $38.4^{\circ}$ and the minimal $2.74^{\circ}$. The range was equal to $35.66^{\circ}$, the $\mathrm{SD}=7.66$.

Based on the conducted test no significant difference was determined in terms of measuring the HT angle before and after the rehabilitation. The p-value significance level was equivalent to 0.0511 . T-test value stood at -2.08 (Figure 5).

\section{Frontal head tilt (FHT) angle}

The highest value of this angle among the researched people was $7.03^{\circ}$ and the lowest was $0.15^{\circ}$, at $\mathrm{SD}=2.16$. The range was at $6.88^{\circ}$, and the average value of the set was $2.71^{\circ}$. After 20 days of training the average FHT angle value decreased to $2^{\circ}$, so the difference in the average values for this angle before and after the training stood at $0.71^{\circ}$ (Figure 6).

Based on the conducted test a significant difference in the value of the FHT angle before and after the training was determined. The conducted training significantly increased the angle with the average difference being $0.71^{\circ}$. The p-value significance level was equivalent to 0.0090 . The t-test value stood at 2.9088 .

\section{Age, work seniority, and work time correlation}

To assess the impact of the age, work seniority, and work time, the Pearson's linear correlation coefficient was used. Based on the conducted test no significant impact was determined in terms of the age, work seniority, and work time on changing the analyzed head and neck angles as a result of the exercises (Table 2).

\section{DISCUSSION}

The head plays a unique role in the biomechanics of the motion system. In physiological conditions it should be located within the prolongation of the body's midline. Such

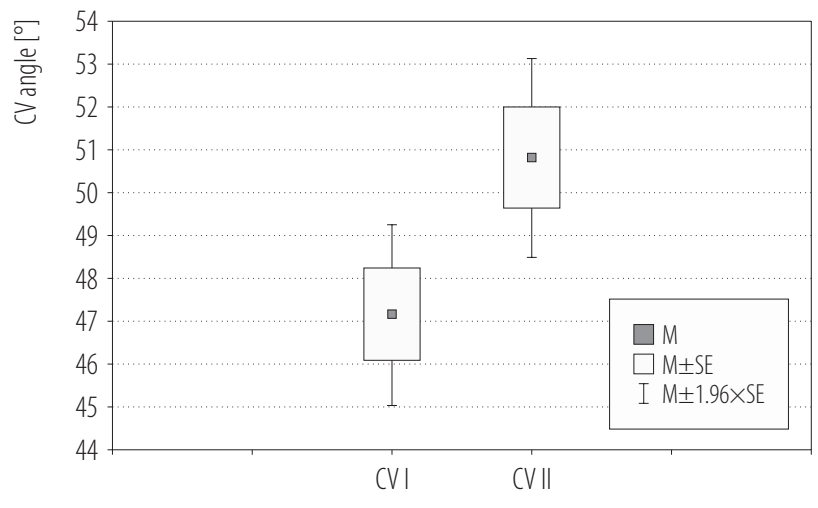

Figure 4. Craniovertebral (CV) angle measurements before (CV I) and after the exercises (CV II)

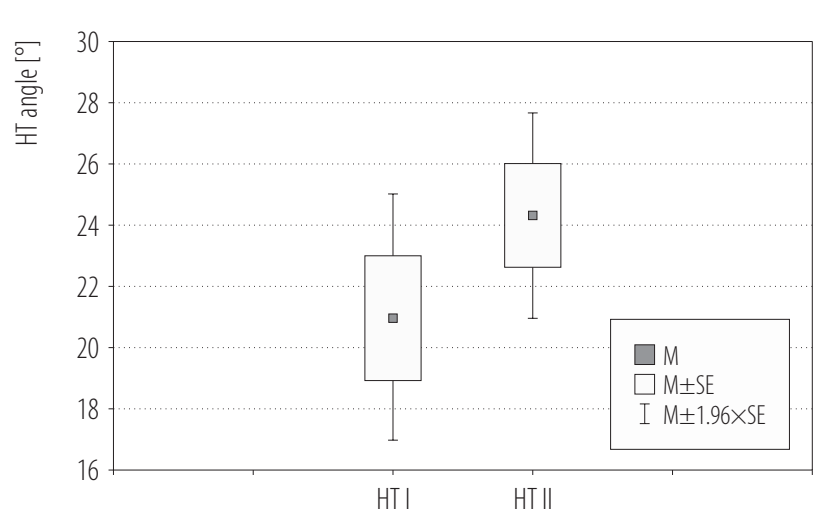

Figure 5. Head tilt (HT) angle measurements before (HT I) and after rehabilitation (HT II)

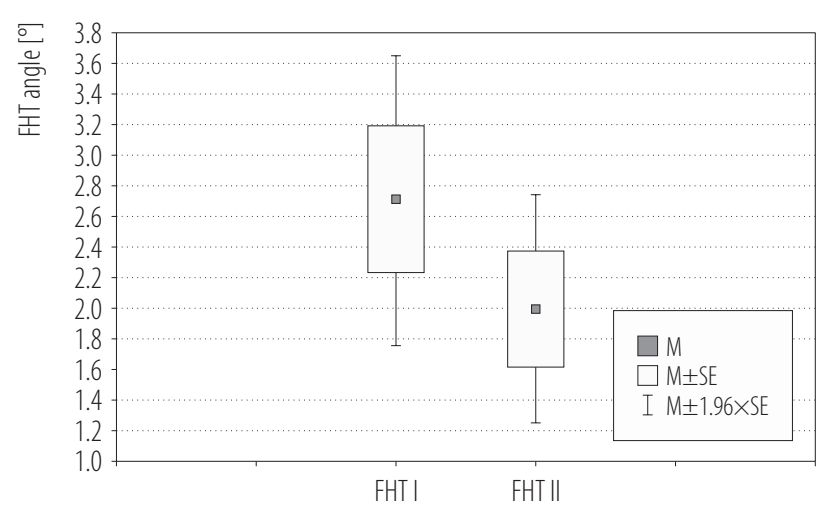

Figure 6. Frontal head tilt (FHT) angle measurements before (FHT I) and after the exercises (FHT II)

a position determines an optimal musculoskeletal balance. In practice, a clinical assessment of the head posture is performed by observation. However, it provides only 
a general image and constitutes just a starting point for further specialist diagnoses.

Such a subjective assessment may be interpreted differently by various therapists due to the difficulties in both determining the norms as well as standardizing the perfect body posture. Passier et al. [18] believe that observation is a useful tool but only to determine deviations larger than $5^{\circ}$ in one of the motion planes. One of the more reliable methods of assessing body posture as well as the spatial position of the head seems to be the photogrammetric method. This is confirmed for example by the results of Weber's research [19]. The procedure of assessing head posture used in terms of this work was also based on photogrammetric research. The research consisted in measuring 3 angles $\mathrm{CV}, \mathrm{HT}$, and FHT. The CV angle provides a general image of the patient, confirming a protracted or retracted head posture. It is generally used in researches described in literature. This angle represents the position of the lower cervical vertebrae. In the case of the forward head posture the value of the $\mathrm{CV}$ angle allows to determine the scope of the angulation within the cervicothoracic junction. A previous study demonstrated that an increased FHP was associated with a decreased CV [20]. If that angle possesses lower values then it stands for limiting the cervical lordosis, a higher angulation of the lower segments, and increasing the compressive forces of that area $[18,11]$. According to Salahzadeh et al. [11] a measurement lower than $48-50^{\circ}$ indicates a head protraction.
Yip et al. [21] reported that participants with a significantly smaller CV angle had FHP and tended to have increased levels of neck pain. Similarly, Sohn et al. [22] showed that participants with smaller craniovertebral angles tended to have more tension-type headaches, and a lower cervical range of motion. The exercises used in this work had an impact on changing the position of the head in the sagittal plane. The average value of the $\mathrm{CV}$ angle before the training was at $47.17^{\circ}$, and $50.82^{\circ}$ after the training. It is significant that as much as $90 \%$ of the people achieved better results after the training, and the measurements improved at more than $4 \%$ for 6 people. For one person the 20 days of training resulted in a retraction of the head and an increase of the angle at $12.78^{\circ}$. In reference to the values of the $\mathrm{CV}$ angle published by other authors, the results of the group prior to the rehabilitation are comparable within the range of $\pm 2^{\circ}[11,19,23]$.

A following angle used for analyzing the head posture in this work was the HT angle. The values of this angle were determined by the position of the higher segments of the cervical spine. This is represented by a situation in which a person follows its head along a downward sight towards own feet. At such a position an angulation of these vertebrae can be seen in the RTG image. Excessive straightening of these vertebrae will be noticeable with people looking up, when the head is positioned in a significant protraction [12,13]. Both Raine and Twomey [12] and Singla et al. [13] describe the fact that an attempt to recreate the physiological angulation of the lower part of the cervical

Table 2. The correlation of age, work seniority, and work time of the 20 female office workers from Kraków, Poland, in regard to the changes in the values of specific angles

\begin{tabular}{lcccccc}
\hline \multicolumn{7}{c}{$\begin{array}{c}\text { Angle } \\
{\left[{ }^{\circ}\right]}\end{array}$} \\
\hline craniovertebral & $\mathrm{p}$ & head tilt & $\mathrm{p}$ & frontal head tilt & $\mathrm{p}$ \\
\hline Age & -0.1542 & 0.516 & -0.1475 & 0.535 & -0.0536 & 0.822 \\
Work seniority & -0.0043 & 0.986 & -0.0719 & 0.763 & -0.1987 & 0.401 \\
Work time & -0.1272 & 0.593 & -0.2352 & 0.318 & -0.2351 & 0.318 \\
\hline
\end{tabular}


spine results in a negative correlation with the upper part of the cervical spine. This means that increasing the lower lordosis is related to reducing the upper cervical spine angulation.

Reports from recent years use the HT angle as a complementation of the head posture assessment within the sagittal plane (CV angle). However, the research included in this work did not determine a significant difference in the numerical values of that angle with people possessing a correct head control in the sagittal plane and with a forward head posture. Therefore, it seems that when assessing the forward head posture this angle constitutes a much less significant diagnostic value than the $\mathrm{CV}$ angle.

An average result of the research group prior to the therapy was $20.99^{\circ}$ for the HT angle. Raine and Twomey [12], as well as Salahzadeh et al. [11] achieved slightly lower results in their research, respectively $11.2^{\circ}$ and $16.1^{\circ}$. It is worth to emphasize than contrary to the CV angle certain forms for the HT angle, or a dependency defining the perfect head position are difficult to be determined. At a physiological posture when the $\mathrm{CV}$ angle is set as $48-50^{\circ}$, the optimal values for the HT angle are between -7 to $+7^{\circ}$. Improving that result at $3.32^{\circ}$ after the therapy does not provide a complete and reliable clinical value for a therapist. Only juxtaposing this data with the CV angle and an observation will allow to determine an improvement of the axial symmetry in reference to the spine. An interesting observation seems to be the following relation: the lower the $\mathrm{CV}$ angle the higher the HT angle. It allows to conclude that a large group of the researched people possesses a forward head posture.

The last of the described angles is the FHT angle which is the only one that allows to assess the position of the head in the frontal plane. Many authors omit this angle in their research. Taking into consideration the described consequences of the body's dysfunction in this plane [7,24] this seems to be an expression of academic ignorance.
The average value for this angle prior to the training was at $2.71^{\circ}(\mathrm{SD}=2.2)$, and $2^{\circ}(\mathrm{SD}=2.6)$ after the training. In comparison, a result of $0.1^{\circ}\left( \pm 2.6^{\circ}\right)$ was achieved in the work by Raine and Twomey [12], and $0.8^{\circ}\left( \pm 2.9^{\circ}\right)$ in the work by Singla et al. [13]. It is true that the closer it gets to $0^{\circ}$ the closer the head posture is to the norm. Taking into consideration the results after the training, the value of the angle was $>2^{\circ}$ for 9 people. For 7 people the value of the angle was $<1^{\circ}$.

Unfortunately, most of the results indicate an incorrect head posture. The relation stating that in time our head posture will become more prone to protraction seems to be logical. The analysis performed by us does not allow to explicitly confirm a precise relation between the age and the values of any of the determined angles. It has to be emphasized that limiting the group to 20 people may not result in a completely objective assessment. It is worth to emphasize the fact that the oldest person in the group achieved scores confirming a correct head posture whereas a person 26 years younger achieved scores close to a serious dysfunction.

Working with the computer is generally viewed as a new risk factor FHP. However, the CV angle value of $44.1^{\circ}$ at the age of 35 and short work seniority (6 years) allows to conclude that working with a computer is not the only factor for a compensatory head posture. This is confirmed by observations performed by Richter et al. who suggest that musculoskeletal disorders in terms of employees working with visual display units are actually related to the employee's individual characteristics [25].

It was also estimated that the amount of daily work in front of the desk and work seniority would have an impact on the axial symmetry of the head. The achieved results did not confirm this relation as well. These results are not confirmed by Riccò et al.'s research [26]. The author believes that employees, with greater computer work experience reported musculoskeletal disorders of the cervical spine more often. 
These discrepancies suggest a need to individually search for the variable factors, which may also impact the head posture regardless of the undertaken work. Park et al. [27] suggest the reason for an abnormal model of positioning the head is the lack of proper knowledge, awareness, and diligence in following the rules of its proper posture. People, most often office workers, do not realize the incorrect neck-head layout. Their subjective belief concerning their posture often differs from the later, real body posture [27].

\section{Limitations}

There were a number of potential limitations. They include: the diverse age of the researched, small number of participants in the study, an identical set of exercises proposed to all participants without taking into consideration a training plan adjusted individually to each person. There was also no control group. Despite that, the study confirmed that selective neck exercises improve head posture. The authors believe that the proposed exercises may be applied not only to women working at the desk but in a much wider population.

\section{CONCLUSIONS}

The results demonstrate that a short, home-based targeted exercise program may improve head posture. These results provide a foundation for further development of postural improvement programs that include an exercise component.

\section{ACKNOWLEDGMENTS}

The authors thank to all the participants.

\section{REFERENCES}

1. Kim BB, Lee JH, Jeong HJ, Cynn HS. Effects of suboccipital release with craniocervical flexion exercise on craniocervival alignment and extrinsic cervical muscle activity in subjects with forward head posture. J Electromyogr Kinesiol. 2016;30:31-7, https://doi.org/10.1016/j.jelekin.2016.05.007.
2. Starrett K, Starrett J, Cordoza G. [Deskbound. Standing up to a sitting world]. Łódź: Galaktyka; 2016. p. 11-47. Polish.

3. Groszek M, Babula G, Nagraba $Ł$, Stolarczyk A, Mitek T. Risks connected with a wrong sitting position. Arthr Joint Surg. 2011;7(3-4):50-61, https://doi.org/10.5604/.969148.

4. Fernández-de-las-Peñas C, Alonso-Blanco C, Cuadrado ML, Pareja JA. Forward head posture and neck mobility in chronic tension-type headache: A blinded, controlled study. Cephalalgia. 2006;26(3):314-9, https://doi.org/10.1111/j.14682982.2005.01042.x.

5. Silva AG, Punt TD, Sharples P, Vilas-Boas JP, Johnson MI. Head posture and neck pain of chronic nontraumatic origin: A comparison between patients and pain-free persons. Arch Phys Med Rehabil. 2009;90(4):669-74, https://doi. org/10.1016/j.apmr.2008.10.018.

6. Griegel-Morris P, Larson K, Mueller-Klaus K, Oatis CA. Incidence of common postural abnormalities in the cervical, shoulder, and thoracic regions and their association with pain in two age groups of healthy subjects. Phys Ther. 1992;72(6):425-31, https://doi.org/10.1093/ptj/72.6.425.

7. Szczygieł E, Węglarz K, Piotrowski K, Mazur T, Mętel S, Golec J. Biomechanical influences on head posture and the respiratory movements of the chest. Acta Bioeng Biomech. 2015;17(2):143-8.

8. Han J, Park S, Kim Y, Choi Y, Lyu H. Effets of forward head posture on forced vital capacity and respiratory muscles activity. J Phys Ther Sci. 2016;28(1):128-31, https://doi. org/10.1589/jpts.28.128.

9. Grimmer-Somers K, Milanese S, Louw Q. Measurement of cervical posture in the sagittal plane. J Manipulative Physiol Ther. 2008;31(7):509-17, https://doi.org/10.1016/ j.jmpt.2008.08.005.

10. Van Niekerk SM, Louw Q, Vaughan C, Grimmer-Somers K, Schreve K. Photographic measurement of upper-body sitting posture of high school students: A reliability and validity study. BMC Musculoskelet Disord. 2008;9(1):113, https:// doi.org/10.1186/1471-2474-9-113. 
11. Salahzadeh Z, Maroufi N, Ahmadi A, Behtash H, Razmjoo A, Gohari M, et al. Assessment of forward posture in females: Observational and photogrammetry methods. J Back Musculoskelet Rehabil. 2014;27(2):131-9, https://doi.org/ 10.3233/BMR-130426.

12. Raine S, Twomey LT. Head and shoulder posture variations in 160 asymptomatic women and men. Arch Phys Med Rehabil. 1997;78(11):1215-23, https://doi.org/10.1016/S00039993(97)90335-X.

13. Singla D, Veqar Z, Hussain, ME. Photogrammetric assessment of upper body posture using postural angles: A literature review. J Chiropr Med. 2017;16(2):131-8, https://doi.org/ 10.1016/j.jcm.2017.01.005.

14. Moon HJ, Goo BO, Cho SH. The effect of cocontraction of the masticatory muscles during neck stabilization exercises on thickness of the neck flexors. J Phys Ther Sci. 2015;27(3):659-61, https://doi.org/10.1589/jpts.27.659.

15. Kobesova A, Dzvonik J, Kolar P, Sardina A, Andel R. Effects of shoulder girdle dynamic stabilization exercise on hand muscle strength. Isokinet Exerc Sci. 2015;23(1):21-32, https://doi.org/10.3233/IES-140560.

16. Lee Y, Shin MMS, Lee W. Effects of shoulder stabilization exercise on pain and function in patients with neck pain. J Phys Ther Sci. 2015;27(12):3619-22, https://doi.org/ 10.1589/jpts.27.3619.

17. Choi DY, Chung SH, Shim JH. Comparisons of shoulder stabilization muscle activities according to postural changes during flexi-bar exercise. J Phys Ther Sci. 2015;27(6):188991, https://doi.org/10.1589/jpts.27.1889.

18. Passier LN, Nasciemento MP, Gesch JM, Haines TP. Physiotherapist observation of head and neck alignment. Physiother Theory Pract. 2010;26(6):416-23, https://doi.org/ 10.3109/09593980903317557.

19. Weber P, Correa ECR, Milanesi JM, Soares JC, Trevisan ME. Craniocervical posture: Cephalometric and bio- photogrammetric analysis. Braz J Oral Sci. 2012;11(3): 416-21.

20. Quek J, Pua YH, Clark RA, Bryant AL. Effects of thoracic kyphosis and forward head posture on cervical range of motion in older adults. Man Ther. 2013;18(1):65-71, https://doi. org/10.1016/j.math.2012.07.005.

21. Yip CH, Chiu TT, Poon AT. The relationship between head posture and severity and disability of patients with neck pain. Man Ther. 2008;13(2):148-54, https://doi.org/10.1016/ j.math.2006.11.002.

22. Sohn JH, Choi HC, Lee SM, Jun AY. Differences in cervical musculoskeletal impairment between episodic and chronic tension-type headache. Cephalalgia. 2010;30(12):1514-23, https://doi.org/10.1177/0333102410375724.

23. Bokaee F, Rezasoltani A, Manshadi DF, Naimi SS, Baghban AA, Azimi H. Comparison of cervical muscle thickness between asymptomatic women with and without forward head posture. Braz J Phys Ther. 2017;21(3):206-11, https:// doi.org/10.1016/j.bjpt.2017.04.003.

24. Szczygieł E, Piotrowski K, Golec J, Czechowska D, Masłoń $\mathrm{A}, \mathrm{Bac} \mathrm{A}$, et al. Head position influence on stabilographic variables. Acta Bioeng Biomech. 2016;18(4):49-54.

25. Richter JM, van den Heuvel SG, Huysmans MA, van der Beek AJ, Blatter BM. Is peak exposure to computer use a risk factor for neck and upper-extremity symptoms? Scand J Work Environ Health. 2012;38(2):155-62, https://doi.org/ 10.5271/sjweh.3196.

26. Riccò M, Cattani S, Gualerzi G, Signorelli C. Work with visual display units and musculoskeletal disorders: A crosssectional study. Med Pr. 2016;67(6):707-19, https://doi. org/10.13075/mp.5893.00471.

27. Park E, Schoner G, Scholz JP. Functional synergies underlying control of upright posture during changes in head orientation. PLOS One. 2012;7(8):1-12, https://doi.org/10. 1371/journal.pone.0041583.

This work is available in Open Access model and licensed under a Creative Commons Attribution-NonCommercial 3.0 Poland License - http://creativecommons.org/ licenses/by-nc/3.0/pl/deed.en. 